\title{
CURRENCY AREAS AND INTERNATIONAL ASSISTANCE
}

\author{
By PierRe M. PiCARd AND TIM WorRALL
}

January 2009

\begin{abstract}
This paper considers a simple stochastic model of international trade with three countries. Two of the tree countries are in an economic union. Comparisons are made between equilibrium welfare for these two countries under fixed and flexible exchange rate regimes. Within the model it is shown that flexible exchange rate regimes generate greater welfare. However, we then consider comparisons of welfare when the two countries also engage in some international assistance in order to share risk. Such risksharing is limited by enforcement constraints of cross border assistance. It is shown that taking into account limited commitment risk-sharing fixed exchange rates or currency areas can dominate flexible exchange rate regimes reversing the previous result.
\end{abstract}

KEYWORDS: Monetary union - currency areas $\cdot$ fiscal federalism $\cdot$ limited commitment $\cdot$ mutual insurance

JEL CLASSIFICATION: F12 · F15 · F31 · F33

\section{INTRODUCTION}

This paper contributes to the theory of optimal currency areas. In an often cited paper Mundell (1961) argues that business cycles should be sufficiently positively correlated for a common currency area to be optimal. Bayoumi (1994) formally shows that when shocks are negatively correlated across countries a currency union is less desirable. As a consequence, the discussion about the UK's integration (or non-integration) into the Euro currency area has often been driven by the fact that UK business cycles are not well correlated with continental Europe. Equally the discussion of when the accession countries should join the Euro currency area has been dominated by the debate about the congruence of the economic cycles of the accession countries and the rest of Europe.

One aspect of monetary integration that has received relatively little attention is the interaction of international assistance and business cycles on the optimality of currency areas. This is an important consideration since, as has been argued by Drèze

Département Economie, University of Luxembourg, 162A avenue de la Faïencerie, L-1511 Luxembourg and CORE, Université Catholique de Louvain, Louvain-la-Neuve, Belgium. E-mail: pierre.picard@uni.lu and Economics, School of Social Sciences, University of Manchester, Oxford Road, Manchester, M13 9PL UK. E-mail: tim.worrall@manchester.ac.uk. 
(2000), transfers between regions can be used as a means of insurance against regional income shocks. ${ }^{1}$ Moreover in the case of the EU, shocks have been shown to be large (Forni and Reichlin 1999) and risk diversification incomplete (French and Poterba 1991, Baxter and Jermann 1997) suggesting that there are welfare gains if more insurance between regions can be agreed. Although interregional transfers in the EU are currently quite small (less than 1\% GDP) they do increasingly depend on regional income (through EU Objective 1 Funds) and further integration is likely to mean that transfers play an increasingly prominent role is smoothing interregional fluctuations. The purpose of this paper is to address that gap and examine the interaction between risk-sharing measures and the optimality of a currency union. It provides a dynamic model of risk-sharing in which the conclusion of Mundell is turned on its head. A currency union can indeed be optimal when the demand for risk sharing is high and shocks are anti-correlated.

To make the contrast with previous results sharp we model a situation where there are nominal wage and price rigidities. This nominal wage and price rigidity would normally mean that there is a need for exchange rate flexibility and hence that a monetary union is inefficient. However, we show that when the risk sharing motivation between countries is taken into account this result may be reversed. We shall not assume that risk sharing is perfect. Indeed we shall show that within the model a currency union will not be optimal if risk sharing is perfect. Rather we assume that risk sharing between countries is limited by self-enforcing constraints. This is natural assumption for a currency union between sovereign states as there is no supra-national legal authority to enforce transfers. Hence countries will only make such transfers if they are in their own long-term interest. This long-term interest will be determined by the future benefits of risk sharing and by the punishment imposed for not making the requisite transfer which we assume involves a loss of future assistance. The importance of the self-enforcement constraints is that the inefficiencies caused by nominal wage and price rigidities may increase the variance of regional incomes in currency unions and this may make it easier to enforce transfers as the consequences of loss of future assistance are more severe. Countries may thus prefer a currency union because greater transfers and insurance can be sustained. That is the benefit of insurance may outweigh the inefficiency cost of a fixed exchange rate and consequent real price rigidities. We shall show that this is indeed possible and that there are circumstances where a monetary union is preferred to the flexible exchange rate system because of the desire to share risk.

\footnotetext{
${ }^{1}$ Our model is also related to the literature on fiscal federalism but in most of that literature the transfers between regions take place because of sharing of a public good, such as security (see also Alesina et al. 1995, Persson and Tabellini 1996), rather than sharing of risk.
} 
Our model is stylized and designed to give an advantage to flexible exchange rates in the absence risk-sharing considerations. In this way we can show that the possibilities of risk sharing can be important for decisions about a currency union. There are many other potential factors which advantage currency unions such as the removal of exchange rate transaction costs, the elimination of competitive inflation and the increased stability of financial markets and so on. Qualitatively the implications of risk sharing will be similar in these models too. What our results show is that the issue of currency integration cannot be divorced from the issue of fiscal integration through international assistance and that international assistance is an important factor to weigh in considering the optimality of a currency union.

For most of this paper we focus on the case where the decision to adopt a common currency or not has no effect on the technology of enforcing risk sharing agreements. ${ }^{2}$ However, it is possible that a common currency will be associated with other political and economic aspects of integration which will improve the enforcement mechanism and thus lead to greater risk sharing. ${ }^{3}$ This will increase the desire for a currency union further and may also be an important benefit of a currency union itself. Our framework also allows us to address this issue and consider when a common currency is better if it also confers benefits in terms of the enforcement technology.

The paper is organized as it follows. Section 2 presents the model and studies the equilibria under common currency area and flexible exchange rates. In Section 3 we study an economy with negatively correlated shocks and show when transfers between countries can be sustained and when a monetary union will deliver higher welfare than a flexible exchange rate system. Section 4 considers extensions to the basic model. These extensions quantitatively modify but do not qualitatively change the main results that the common currency system sustains greater levels of transfers and may therefore lead to higher welfare for certain parameter values showing that the model is robust at least to these generalizations. Section 5 concludes. An Appendix contains the proofs.

\section{BASIC MODEL}

We consider a simple model of international trade with three countries $r=H, F, W$ (Home, Foreign and the rest of the World). We consider that Home and Foreign have close economic ties or are in an economic union and shall be interested in whether Home and Foreign should operate a currency union or retain a flexible exchange rate regime. This is the situation of the UK or accession countries and the Euro area

\footnotetext{
2 This will be made precise below.

${ }^{3}$ Historically, many countries like the U.S.A., U.K., France and others have adopted a common currency before implementing considerable redistributive systems between their sub-national jurisdictions.
} 
countries or between Canada or Mexico and the US. In order to make the comparison between fixed and flexible exchange rates non-trivial we shall assume that there are some market imperfections in the labor and product markets. Following much of the literature on currency areas we shall assume that labor is immobile across countries and that the labor market is subject to nominal rigidities. However, we shall assume there is free and frictionless trade between countries. ${ }^{4}$ Further we shall assume that the goods markets in the Home and Foreign countries is monopolistically competitive with a continuum of varieties produced and price setting by firms. In the rest of the world firms produce a homogenous good which we label $W$.

There is a unit mass of consumer-workers in country $H$ and the same mass in country $F$. In country $W$ there is also a unit mass of consumer-workers. ${ }^{5}$ Labor is supplied inelastically in each country. We shall assume that goods are non-storable and that consumers consume both domestically-produced and foreign-produced goods. We shall index goods by $\varsigma$ or $\xi$ and let $d_{r s}(\xi)$ denote the demand for good of variety $\xi$ from consumers in country $r$ which is produced in country $s$. Similarly we let $d_{r W}$ denote the demand for good $W$ in country $r$. Individuals in all countries have the same Dixit and Stiglitz (1977) type preference function

$$
V\left(C_{r}\right)=V\left(\left(\int_{0}^{1} d_{r r}(\varsigma)^{\frac{\sigma-1}{\sigma}} d \varsigma+\int_{0}^{1} d_{r s}(\xi)^{\frac{\sigma-1}{\sigma}} d \xi\right)^{\frac{\sigma \mu}{\sigma-1}} d_{r W}^{1-\mu}\right)
$$

where $V$ is assumed to be strictly increasing and strictly concave reflecting the fact that agents are assumed to be risk averse, ${ }^{6} C_{r}$ is the aggregate composite good in country $r$ and $\sigma>1$ is the elasticity of substitution. The elasticity $\sigma$ is a measure of the degree of competition between firms and the higher is $\sigma$ the greater will be the degree of competition between firms across countries. The parameter $\mu$ measures the relative importance of the rest of the World. If $\mu$ is close to one then the rest of the World has little importance and we are left with a two country model. If $\mu$ is small then the rest of the world is more important so there is a smaller need of insurance between countries $H$ and $F$ under flexible exchange rates. Letting $p_{r s}(\varsigma)$ denote the price of good $\varsigma$ sold in country $r$ and produced in country $s$, the budget

\footnotetext{
${ }^{4}$ Although we assume there are no transport or transactions costs to trade, these can be added to the model without substantially changing the conclusions of the paper. Without transport costs a currency union is never desirable without the insurance motives we model here. Thus introducing transportation costs will tend to strengthen our conclusions.

${ }^{5}$ Nothing will hinge on the relative size of country $W$ and the assumption of a unit mass for the rest of the world is made purely for convenience.

${ }^{6}$ For some of the subsequent analysis and the numerical calculations we shall assume that the utility function exhibits constant relative risk aversion preferences.
} 
constraint for the representative agent in country $r$ is

$$
\int_{0}^{1} d_{r H}(\varsigma) p_{r H}(\varsigma) d \varsigma+\int_{0}^{1} d_{r F}(\xi) p_{r F}(\xi) d \xi+p_{r W} d_{r W}=Y_{r}+T_{r}
$$

where $Y_{r}$ is the income of consumers in country $r$ and $T_{r}$ is the transfer income received by country $r$ expressed in the own countries currency. As we are examining an economic union between $H$ and $F$ we shall consider transfers only between the Home and Foreign country and ignore transfers with the rest of the world, that is we set $T_{W} \equiv 0$. With the utility function given in (1) the demand for variety $\varsigma$ produced in country $s$ from consumers in country $r$ is

$$
d_{r s}(\varsigma)=\mu \frac{p_{r s}(\varsigma)^{-\sigma}\left(Y_{r}+T_{r}\right)}{P_{r}^{1-\sigma}}
$$

where $P_{r}$ is a price index for goods produced in $H$ and $F$

$$
P_{r}=\left(\int_{0}^{1} p_{r r}(\varsigma)^{1-\sigma} d \varsigma+\int_{0}^{1} p_{r s}(\xi)^{1-\sigma} d \xi\right)^{\frac{1}{1-\sigma}}
$$

Likewise the demand for good $W$ in country $r$ is $d_{r W}=(1-\mu)\left(Y_{r}+T_{r}\right) / p_{r W}$ where $p_{r W}$ is the price of good $W$ in country $r$.

As is well-known the composite consumption is linear in income

$$
C_{r}=\mu^{\mu}(1-\mu)^{1-\mu} \frac{Y_{r}+T_{r}}{P_{r}^{\mu} p_{r W}^{1-\mu}} .
$$

It will be convenient to emphasize the dependence of the composite consumption on the transfer and write it as a function of the transfer received $C_{r}(T)$.

The exchange rate between currencies in the two countries $H$ and $F$ will depend on whether there is a single currency area or a flexible exchange rate. However, in either case, since we have assumed there is free and frictionless trade, prices satisfy $p_{r s}=\varepsilon_{r s} p_{s s}$ for all $r \neq s$, where $\varepsilon_{r s}$ is the exchange rate that converts currency of country $s$ into the currency of country $r$. Since trade is frictionless $\varepsilon_{r s}=1 / \varepsilon_{s r}$. With three countries there are two independent exchange rates and we shall write $\varepsilon$ for $\varepsilon_{H F}$ and $\eta$ for $\varepsilon_{H W}$. Thus $\varepsilon_{F W}=\varepsilon / \eta$. For convenience we shall also write $p_{r}(\varsigma)$ for $p_{r r}(\varsigma)$ and $p_{W W}=p_{W}$. Therefore $p_{H F}(\varsigma)=\varepsilon p_{F}(\varsigma), p_{F H}(\xi)=p_{H}(\xi) / \varepsilon$ and $p_{H W}=\eta p_{W}$. Then it is easy to check from equation (3) that $P_{H}=\varepsilon P_{F}$ and $p_{F W}=p_{H W} / \varepsilon$. As there are no transfers from outside $H$ and $F, T_{H}=-\varepsilon T_{F}$. In the case of a common currency area $\varepsilon=1$. 
We now consider firm behavior. Let $Y=Y_{H}+\varepsilon Y_{F}+\eta Y_{W}$ denote total world income measured in the Home currency. ${ }^{7}$ For firms producing variety $\varsigma$ in country $H$ the demand they face from Home and other consumers in $F$ and $W$ is

$$
\begin{aligned}
d_{H}(\varsigma) & =\mu\left(\frac{p_{H}(\varsigma)^{-\sigma}\left(Y_{H}+T_{H}\right)}{P_{H}^{1-\sigma}}+\frac{\left(\frac{p_{F}(\varsigma)}{\varepsilon}\right)^{-\sigma}\left(Y_{F}+T_{F}\right)}{P_{F}^{1-\sigma}}+\frac{\left(\frac{p_{W}}{\eta}\right)^{-\sigma} Y_{W}}{P_{W}^{1-\sigma}}\right) \\
& =\mu \frac{p_{H}(\varsigma)^{-\sigma}}{P_{H}^{1-\sigma}} Y .
\end{aligned}
$$

Since $P_{H}=\varepsilon P_{F}$ and $T_{H}=-\varepsilon T_{F}$ demand is given by

(5) $d_{H}(\varsigma)=\mu \frac{p_{H}(\varsigma)^{-\sigma}}{P_{H}^{1-\sigma}} Y ; \quad d_{F}(\xi)=\mu \frac{p_{H}(\varsigma)^{-\sigma}}{P_{H}^{1-\sigma}} \frac{Y}{\varepsilon} ; \quad d_{R}=(1-\mu) \frac{1}{p_{W}} \frac{Y}{\eta}$.

Costs are determined by labor requirements which are given by a fixed coefficient technology where to produce one unit of output in country $r$ requires $a_{r}$ units of labor. The price of labor is denoted by $w_{r}$. However, we assume that the labor market is imperfect and that nominal wages are fixed and therefore normalize $w_{r}=1 .{ }^{8}$ With flexible exchange rates the exchange rates will adjust to achieve full employment in each country. However, if there is a common currency between countries $H$ and $F$, the nominal rigidity in wages will cause unemployment in the relatively unproductive country. In Section 3 we shall assume that $a_{H}$ and $a_{F}$ are stochastic and specify a simple stochastic process. However, because input decisions will be made once $a_{r}$ is known and since there are no intertemporal linkages in production or consumption we can determine equilibria as if $a_{r}$ were given. In country $W, a_{W}=1$ and we assume that firms are perfectly competitive. Thus we normalize so that $p_{W}=1$ which in turn implies $p_{H W}=\eta$ and $p_{F W}=\eta / \varepsilon$. In countries $H$ and $F$ firms are assumed to be monopolistically competitive and will set prices to maximize profits given wage costs and demand functions. Given the fixed coefficients and the iso-elastic demand functions given in equation (2), prices are set at a mark-up over cost

$$
p_{r}(\varsigma)=\frac{\sigma}{\sigma-1} a_{r}, \quad r \in\{H, F\}
$$

\footnotetext{
${ }^{7}$ Note that transfers do not affect world demand.

${ }^{8}$ Assuming that nominal wages are completely inflexible is obviously an extreme assumption which we make for convenience only. As argued by Mundell (1961) this a priori makes a currency union less desirable.
} 
It follows from equation (6) that all firms in countries $H$ and $F$ set the same price which is simply a mark-up over costs. This mark-up depends on the elasticity of substitution between commodities. As suggested above the elasticity of substitution is a measure of competition. When substitution is perfect $(\sigma=\infty)$ there is perfect competition and price equal marginal cost. When $\sigma$ is close to one mark-ups become large. It also follows from equation (6) that demand is the same for all varieties $d_{r}(\varsigma)=d_{r}$ in a given country. Thus total labor demand is simply $\ell_{r}=a_{r} d_{r}$. By assumption all profits accrue to firms' owners and for convenience we assume that all profits are spent locally. Thus the national income in country $r$ is $Y_{r}=p_{r} d_{r}=p_{r} \ell_{r} / a_{r}$. Using equation (6) national income is

$$
Y_{H}=\frac{\sigma}{\sigma-1} \ell_{H} \quad \text { and } \quad Y_{F}=\frac{\sigma}{\sigma-1} \ell_{F}
$$

Since $p_{W}=1, \ell_{W}=1$ and $a_{W}=1$, national income in $W$ is $Y_{W}=1$. Equally the price index of equation (3) can be re-written using equation (6) as

$$
P_{H}=\left(p_{H}^{1-\sigma}+\varepsilon^{1-\sigma} p_{F}^{1-\sigma}\right)^{\frac{1}{1-\sigma}}=\frac{\sigma}{\sigma-1}\left(a_{H}^{1-\sigma}+\varepsilon^{1-\sigma} a_{F}^{1-\sigma}\right)^{\frac{1}{1-\sigma}}=\varepsilon P_{F} .
$$

An equilibrium is then a set of prices and demands such that (i) consumers maximize their utility given their budget constraint and given prices, (ii) firms set their profit maximizing prices and (iii) product markets clear. Since the labor market is imperfect in countries $H$ and $F$ we do not assume that the labor market clears and there may be some situations, discussed below, where there is unemployment. Whether labor markets clear or not, the product demand equal product supply conditions are derived from equations (5) and the fixed coefficient technology as

$$
\mu \frac{p_{H}(i)^{-\sigma} Y}{P_{H}^{1-\sigma}}=\frac{\ell_{H}}{a_{H}} \quad \text { and } \quad \mu \frac{p_{F}(i)^{-\sigma}\left(\frac{Y}{\varepsilon}\right)}{P_{F}^{1-\sigma}}=\frac{\ell_{F}}{a_{F}}
$$

together with the rest of the World condition $\eta=(1-\mu) Y$. Using the fact that $P_{H}=\varepsilon P_{F}$ and $p_{H} / p_{F}=a_{H} / a_{F}$ and taking the ratio of the two equations in (8) gives expressions for the two exchange rates

$$
\varepsilon=\left(\frac{a_{H}}{a_{F}}\right)^{\frac{\sigma-1}{\sigma}}\left(\frac{\ell_{H}}{\ell_{F}}\right)^{\frac{1}{\sigma}} \quad \text { and } \quad \eta=\frac{\sigma(1-\mu)}{(\sigma-1) \mu}\left(\ell_{H}+\varepsilon \ell_{F}\right)
$$


These conditions will determine either the exchange rates $\varepsilon$ and $\eta$ or if $\varepsilon$ is fixed the first condition determines level of employment in either country $H$ or $F$. Note that because all product markets clear, Walras's law implies that trade is also balanced.

\subsection{Common currency area}

We now consider the equilibrium in which countries $H$ and $F$ form a common currency area so that $\varepsilon=1$. In this case the price index is the same in both countries, $P_{H}=P_{F}$. Letting $P$ denote this common index,

$$
P=\left(p_{H}^{1-\sigma}+p_{F}^{1-\sigma}\right)^{\frac{1}{1-\sigma}}=\frac{\sigma}{\sigma-1}\left(a_{H}^{1-\sigma}+a_{F}^{1-\sigma}\right)^{\frac{1}{1-\sigma}} .
$$

There are two cases to consider depending on the sign of $a_{H}-a_{F}$. If $a_{H}<a_{F}$ the Home country is relatively more productive and requires less labor to produce any given quantity of output. With this parametrization and fixed wages it is easy to check that a share of country $F$ 's labor force will be unemployed, $\ell_{F}<1$, as its costs will be higher and hence demand will be lower. In contrast there will be full employment, $\ell_{H}=1$, in country $H$. It therefore follows from equation (9) that $\ell_{F}=\left(a_{H} / a_{F}\right)^{\sigma-1}<1$. If on the other hand $a_{H}>a_{F}$ then there will be unemployment in the Home country and $\ell_{H}=\left(a_{H} / a_{F}\right)^{1-\sigma}<1=\ell_{F}$. Using equation (4) and the price index $P$ given by equation (10), the composite consumption in each of the two countries is

$$
C_{r}^{c}(T)=\mu\left(\ell_{r}+\left(\frac{\sigma-1}{\sigma}\right) T\right)\left(\ell_{H}+\ell_{F}\right)^{(\mu-1)}\left(a_{H}^{1-\sigma}+a_{F}^{1-\sigma}\right)^{\frac{\mu}{\sigma-1}}
$$

where $r=H, F$ and where the superscript $c$ denotes that the consumption is under a currency union. Hence the level of employment in the two countries is given as $\ell_{H}=\min \left\{\left(a_{H} / a_{F}\right)^{1-\sigma}, 1\right\}$ and $\ell_{F}=\min \left\{\left(a_{H} / a_{F}\right)^{\sigma-1}, 1\right\}$.

\subsection{Flexible exchange rate system}

We now consider equilibrium output and consumption under a flexible exchange rate regime. The introduction of an exchange rate provides an additional instrument to allow relative prices to alter and production and employment to increase. Although nominal wages are fixed at $w_{H}=w_{F}=1$ the exchange rate allows the relative wages $\varepsilon w_{F} / w_{H}$ to adapt. Under a flexible exchange rate regime there is no real wage rigidity so that labor markets clear in both the high and low productivity countries, i.e. $\ell_{H}=\ell_{F}=1$. Then equilibrium output in both $H$ and $F$ is $Y_{H}=Y_{F}=\sigma /(\sigma-1)$ 
and the two exchange rates are determined from (9):

$$
\varepsilon=\left(\frac{a_{H}}{a_{F}}\right)^{\frac{\sigma-1}{\sigma}} \text { and } \eta=\frac{\sigma(1-\mu)}{(\sigma-1) \mu}(1+\varepsilon) .
$$

If $a_{H}<a_{F}$ then country $F$ has relatively low productivity and its currency depreciates making its exports relatively cheaper to the Home country. Likewise if $a_{H}>a_{F}$ then country $F$ is relatively more productive and its currency will appreciate so that its exports become relatively more expensive to the Home country. With this exchange rate adjustment and remembering that $P_{H}=\varepsilon P_{F}$, the composite consumption in the Home country is given from equation (4) as

$$
C_{H}^{f}(T)=\mu\left(1+\left(\frac{\sigma-1}{\sigma}\right) T\right)(1+\varepsilon)^{(\mu-1)}\left(a_{H}^{1-\sigma}+\varepsilon^{1-\sigma} a_{F}^{1-\sigma}\right)^{\frac{\mu}{\sigma-1}}
$$

where the superscript $f$ indicates that the consumption is calculated under flexible exchange rates and where the exchange rate $\varepsilon$ is as given in equation (11). Likewise $C_{F}^{f}(T)=\varepsilon C_{H}^{f}(T)$.

\subsection{Risk and risk sharing}

Shocks to productivity will change prices and hence consumptions. A domestic productivity improvement say, leads to a fall in the prices of domestics products and, since the elasticity of substitution is greater than one, a more than proportionate shift of consumers' demand toward those products. Domestic sales and exports increase whereas foreign sales and exports falls. With a fixed exchange rate domestic consumption increases relative to foreign consumption. In a flexible exchange rate regime, the domestic currency appreciates but does not fully compensate the foreign country for its relative loss of competitiveness. Foreign consumers and workers are still relatively worse off. Thus shocks to productivity produce fluctuations in countries' wealth and create a desire for risk sharing even in the case of a flexible exchange rate regime. ${ }^{9}$ In the next section we shall examine a special case where productivity shocks are negatively correlated and hence there will be a strong desire for risk sharing.

Before examining risk sharing we consider the benchmark case where there no transfers between countries. In the absence of transfers, an appropriate exchange rate policy is one that achieves the highest aggregate consumption. One readily shows that $C_{r}^{f}(0) \geq C_{r}^{c}(0)$ for $r=H, F$. Thus we have the standard result

\footnotetext{
${ }^{9}$ If preferences were Cobb-Douglas (corresponding to $\sigma=1$ ) then the terms of trade fully absorb the effect of the productivity shocks and there is no need for inter-regional risk sharing.
} 
PROPOSITION 1: In the absence of any transfers $\left(T_{r}=0\right)$, aggregate consumption at any state is higher under flexible exchange rate system: $C_{r}^{f}(0) \geq C_{r}^{c}(0), r=H, F$.

Proposition 1 shows that if there are no transfers between countries $H$ and $F$ then a common currency area will always be dominated by a flexible exchange rate regime. Thus if in our model a common currency is desirable it derives from the risk-sharing motive.

\section{CURRENCY AREAS UNDER NEGATIVELY CORRELATED SHOCKS}

We shall now consider transfers between countries $H$ and $F$ and how this affects the result that a flexible exchange rate regime dominates a common currency area that we have seen in Proposition 1. To do this we will need to specify a stochastic process for productivity shocks so that there are some potential mutual gains to transfers. The role of shocks has often played a key role in debates about common currency areas. Taking into account transactions costs Mundell (1961) argues that business cycles should be sufficiently positively correlated for a common currency area to be optimal. Bayoumi (1994) formally shows that negative correlation of shocks makes currency unions less desirable. As a consequence, the discussion about the UK's integration or non-integration in the Euro currency area has often been driven by the fact that UK business cycles are not well correlated with continental Europe.

In this section we shall show that the conclusion of Mundell (1961) can be reversed when self-enforcing transfers are taken into account. That is it is shown that a common currency area can be optimal when shocks are negatively correlated. To do this we take the extreme assumption that shocks are perfectly negatively correlated. Thus we will make assumptions, absence of transactions costs and negatively correlated shocks, that are usually seen as inimical to currency unions, yet show that a common currency area can be optimal in these circumstances. Our argument lies in the fact that when there are productivity shocks and income variability across countries it will be desirable to try and smooth these shocks by making transfers between countries. However, transfers across countries may be difficult to legally enforce and therefore such insurance transfers must be self-enforcing and enforcement may sometimes be helped by the threat of a more severe punishment.

To proceed we shall assume that the technology in countries $H$ and $F$ is stochastic. We shall assume there are just two symmetric states, so that the two countries either have a good or a bad productivity shock. Further we suppose that these states are perfectly negatively correlated states so that the labor requirements are $\left(a_{H}, a_{F}\right)=(z, 1)$ in state 1 and $\left(a_{H}, a_{F}\right)=(1, z)$ in state 2 . We assume that $z<1$ so that the Home country has a good productivity shock is state 1 and the Foreign 
country has the good productivity shock in state 2 . To preserve symmetry we assume that each state occurs with equal probability. With these assumptions, the aggregate composite consumption under the common currency in the two states is given by

$$
\begin{aligned}
& C_{G}^{c}(T)=\mu\left(1+\left(\frac{\sigma-1}{\sigma}\right) T\right) z^{(\mu-1)(\sigma-1)}\left(1+z^{1-\sigma}\right)^{\frac{\sigma(\mu-1)+1}{\sigma-1}} \\
& C_{B}^{c}(T)=\mu\left(z^{\sigma-1}+\left(\frac{\sigma-1}{\sigma}\right) T\right) z^{(\mu-1)(\sigma-1)}\left(1+z^{1-\sigma}\right)^{\frac{\sigma(\mu-1)+1}{\sigma-1}}
\end{aligned}
$$

where $C_{G}^{c}(T)$ is the consumption of the Home (Foreign) country in state 1 (2) when it experiences a good productivity shock and $C_{B}^{c}(T)$ is the consumption of the Home (Foreign) country in state 2 (1) when it experiences a bad productivity shock. The transfer $T$ is the amount received and expressed in the countries own currency. Since $z^{\sigma-1}<1$ it can be seen that absent any transfers the Home (Foreign) country has higher consumption in state 1 (2), when it experiences a positive productivity shock.

Under the flexible exchange rate regime the exchange rate in is $\varepsilon_{1}=z^{\frac{\sigma-1}{\sigma}}<1$ in state 1 as the Foreign currency depreciates when the Home country has a positive productivity shock. In contrast, in state 2 when the Foreign country has a positive productivity shock its exchange rate appreciates to $\varepsilon_{2}=z^{\frac{1-\sigma}{\sigma}}>1$. Then calculating the aggregate composite consumption in each state gives

$$
C_{G}^{f}(T)=\mu\left(1+\left(\frac{\sigma-1}{\sigma}\right) T\right) z^{\frac{1-\sigma}{\sigma}}\left(1+z^{\frac{1-\sigma}{\sigma}}\right)^{\frac{\sigma(\mu-1)+1}{\sigma-1}}
$$

and $C_{B}^{f}(T)=z^{\frac{\sigma-1}{\sigma}} C_{G}^{f}(T)$. As $z^{\frac{\sigma-1}{\sigma}}<1$ it can be seen that absent any transfers the Home (Foreign) country has higher consumption in state 1 (2) when it has positive productivity shock than in state $2(1)$, i.e. $C_{G}^{f}(0)>C_{B}^{f}(0)$.

\subsection{First-best transfers}

In this section we determine the first-best transfers and show that if the first-best transfers are implemented, then the flexible exchange rate regime yields greater welfare. The first-best transfers will equalize composite consumptions whether countries have good or bad productivity shocks. Let $\tau_{*}^{i}$ denote the transfer received by the country with the bad productivity shock under regime $i \in\{c, f\}$. This will be the transfer received by the Home (Foreign) country in state 2 (1).

With a common currency the transfer received by the country with the bad productivity shock equals the transfer made by the country with the good productivity shock. Thus the first-best transfer can be found by solving $C_{G}^{c}(-\tau)=C_{B}^{c}(\tau)$. Calculating 
this transfer and the first-best composite consumption $C_{*}^{c}$

$$
\tau_{*}^{c}=\frac{1}{2} \frac{\sigma}{\sigma-1}\left(1-z^{\sigma-1}\right) \quad \text { and } \quad C_{*}^{c}=\frac{1}{2} \mu z^{\mu(\sigma-1)}\left(1+z^{1-\sigma}\right)^{\frac{\mu \sigma}{\sigma-1}}
$$

As $z^{\sigma-1}<1$, the transfer $\tau_{*}^{c}$ is positive and decreasing in $z$ (a larger value of $z$ is a smaller shock). Therefore in this simple model transfers are independent of the rest of the World. This is for two reasons. First, the transfer has no effect on world income $Y$ and secondly the effect of the degree of preference for rest of the World goods, $\mu$ is symmetric across states.

Under flexible exchange rates if $\tau_{*}^{f}$ is received by the country with the bad productivity shock then the transfer made by the country with the good productivity shock is $z^{\frac{\sigma-1}{\sigma}} \tau_{*}^{f}$. In state 1 (2) it is the Home (Foreign) country which has the good productivity shock so the transfer made is $\varepsilon_{1} \tau_{*}^{f}\left(\tau_{*}^{f} / \varepsilon_{2}\right)$ where $\varepsilon_{1}=z^{\frac{\sigma-1}{\sigma}}=1 / \varepsilon_{2}$. The first-best transfer is therefore found by solving $C_{G}^{f}\left(-z^{\frac{\sigma-1}{\sigma}} \tau_{*}^{f}\right)=C_{B}^{f}\left(\tau_{*}^{f}\right)$. This gives the first-best transfer and consumption

$$
\tau_{*}^{f}=\frac{1}{2} \frac{\sigma}{\sigma-1}\left(z^{\frac{1-\sigma}{\sigma}}-1\right) \quad \text { and } \quad C_{*}^{f}=\frac{1}{2} \mu\left(1+z^{\frac{1-\sigma}{\sigma}}\right)^{\frac{\mu \sigma}{\sigma-1}} .
$$

Since $z^{\frac{1-\sigma}{\sigma}}>1$, the transfer is positive and decreasing in $z$. Again this transfer does not affect $Y$ and is independent of $\mu$.

It is natural to expect that lower consumption with no transfers implies lower consumption under full insurance and this is demonstrated in the next proposition.

PROPOSITION 2: First best transfers yield higher aggregate utility under flexible exchange rate system: $C_{*}^{f} \geq C_{*}^{c}$.

Proposition 2 shows that if it were possible to sustain the first-best transfers then the common currency area would be sub-optimal. Thus we know from Propositions 1 and 2 that if either first-best transfers or no transfers are sustainable then the flexible exchange rate dominates. This should not be a surprise. We have deliberately set up the model to give advantages to the flexible exchange rate regime. We shall however, be interested in cases where the common currency regime sustains more insurance than the flexible exchange rate regime. Before doing so it will be useful to consider parameter values for which the common currency regime with first-best transfers may dominate the flexible exchange rate regime with no transfers.

The common currency regime with first-best transfers generates utility $V\left(C_{*}^{c}\right)$. The flexible exchange rate regime with no transfers generates expected utility 
$\mathrm{E}\left[V\left(C^{f}(0)\right)\right]=(1 / 2) V\left(C_{B}^{f}(0)\right)+(1 / 2) V\left(C_{G}^{f}(0)\right)$. The common currency regime with first-best transfers will dominate when agents are highly risk averse and when the uncertainty is high; in this case, the agents strongly favor the constant consumption in the common currency area. Highly risk averse agents will prefer the regime yielding the highest level of the worst consumption $C_{*}^{c}$ or $C_{B}^{f}(0)$. When $z$ tends to zero so that shocks are very large, the ratio $C_{*}^{c} / C_{B}^{f}(0)$ tends to infinity, which makes the common currency area a better alternative. Equally the ratio $C_{*}^{c} / C_{B}^{f}(0)$ tends to 1 from above if and only if $\sigma<1 / \mu$. Thus low values of the elasticity of substitution and large risk aversion a common currency will be better even for small shocks. Conversely if the elasticity of substitution is large $(\sigma>1 / \mu)$, which is always the case if $\mu=1$, then the flexible exchange rate regime always dominates for sufficiently small shocks no matter what the degree of risk aversion. This will be more generally true if agents are not too risk averse and shocks are small. Then it is to be expected that the flexible exchange rate regime with no transfers will dominate; agents accept the risk of a fluctuating consumption for the benefit of price flexibility. To further examine this interaction between the degree of risk aversion and the degree of uncertainty in more detail we will use the utility function exhibiting a constant coefficient of relative risk aversion (CRRA)

$$
V(C)= \begin{cases}\frac{C^{1-\gamma}}{1-\gamma} & \text { if } \gamma>0 \text { and } \gamma \neq 1 \\ \ln (C) & \text { if } \gamma=1\end{cases}
$$

where $\gamma$ is the coefficient of relative risk aversion. ${ }^{10}$

PROPOSITION 3: For any level of constant relative risk aversion $\gamma$, there exist a threshold $\hat{z} \in(0,1)$ such that (i) the common currency regime with first-best transfers dominates the flexible exchange rate regime with no transfers if $z<\hat{z}$ (shocks are large) and (ii) the latter dominates the former if $z>\hat{z}$ (shocks are small).

Figure 1 provides an illustration of the proposition showing how $\hat{z}$ varies with $\sigma$ and $\gamma$. The locus of indifference between the common currency regime with first-best transfers and the flexible exchange rate regime with no transfers is drawn for three different values of the coefficient of relative risk aversion $\gamma .{ }^{11}$ To the left of each line $z<\hat{z}$ so that $V\left(C_{*}^{c}\right)>\mathrm{E}\left[V\left(C^{f}(0)\right)\right]$ and the common currency regime with first-best transfer dominates the flexible exchange rate regime with no transfers. We see that for

\footnotetext{
${ }^{10}$ We use the constant relative risk aversion function below for our numerical calculations but none of the results hinge on this assumption.

${ }^{11}$ The figure is drawn for $\mu=0.05$. Larger values of $\mu$ slightly shifts the curves to the left without qualitatively affecting the result.
} 
small $z$, that is large shocks, the common currency regime with first-best risk sharing dominates the flexible exchange rate regime with no transfers. With low degrees of substitutability, that is when the environment is not very competitive (small $\sigma$ ), larger shocks are required to preserve this dominance. Similarly as the risk aversion parameter is decreased the common currency with first-best transfers dominates only for larger shocks. ${ }^{12}$ Conversely if the risk aversion parameter is large the common currency with first-best transfer will be better than the flexible exchange rate regime without transfers.

Proposition 3 is an important result in its own right. It shows that despite the model being designed to give an advantage to the flexible exchange rate regime (inflexible labor market, price rigidities, anti-correlated shocks), a common currency can be optimal if it is associated with more redistribution of resources than would occur under a flexible exchange rate regime. The rest of the paper will address the issue of why a common currency area may be associated with more redistribution of resources.

Our argument will rely on two key premises. First the extent to which redistribution can take place is limited and second that the choice of exchange rate regime does not in itself affect the technology for enforcing redistributional transfers.

The first assumption need not apply in all circumstances. For example, if we think of the common currency at the national level then redistribution between national regions can be achieved by decree, constitution or through central tax and subsidies enforced by a common judicial authority. However, the extent of redistribution between independent jurisdictions is likely to be more limited as each jurisdiction must have an incentive to maintain its participation. ${ }^{13}$ Thus we believe that the degree to which redistributional transfers can be sustained is an important one. This issue of sustainability will be the focus of the next sub-sections.

The second assumption is made for expositional purposes. One might argue directly that regions that have a common currency are also those which might foster other institutional mechanisms that can better support redistributional systems. In

${ }^{12}$ If countries are risk-neutral $(\gamma \rightarrow 0)$ then the welfare evaluation is made in terms of expected consumption and the flexible exchange rate regime always dominates.

${ }^{13}$ It is worthwhile to note that some countries do implement additional specific redistribution mechanisms between their sub-national jurisdictions. For instance, the "equalization payments" expressed in the Constitution Act 36(2) in Canada, the Barnett formula in the U.K., the "fiscal horizontal equalization payments" of Landerfinanzausgleich in Germany and the "intervention de solidarité nationale" in Belgium. Even though most of those schemes have legal grounds, their actual implementation is subject to thorough discussions and/or negotiations within governments and parliaments. Thus the sustainability of redistributional schemes is a critical factor even in cases where there is a strong central authority. 


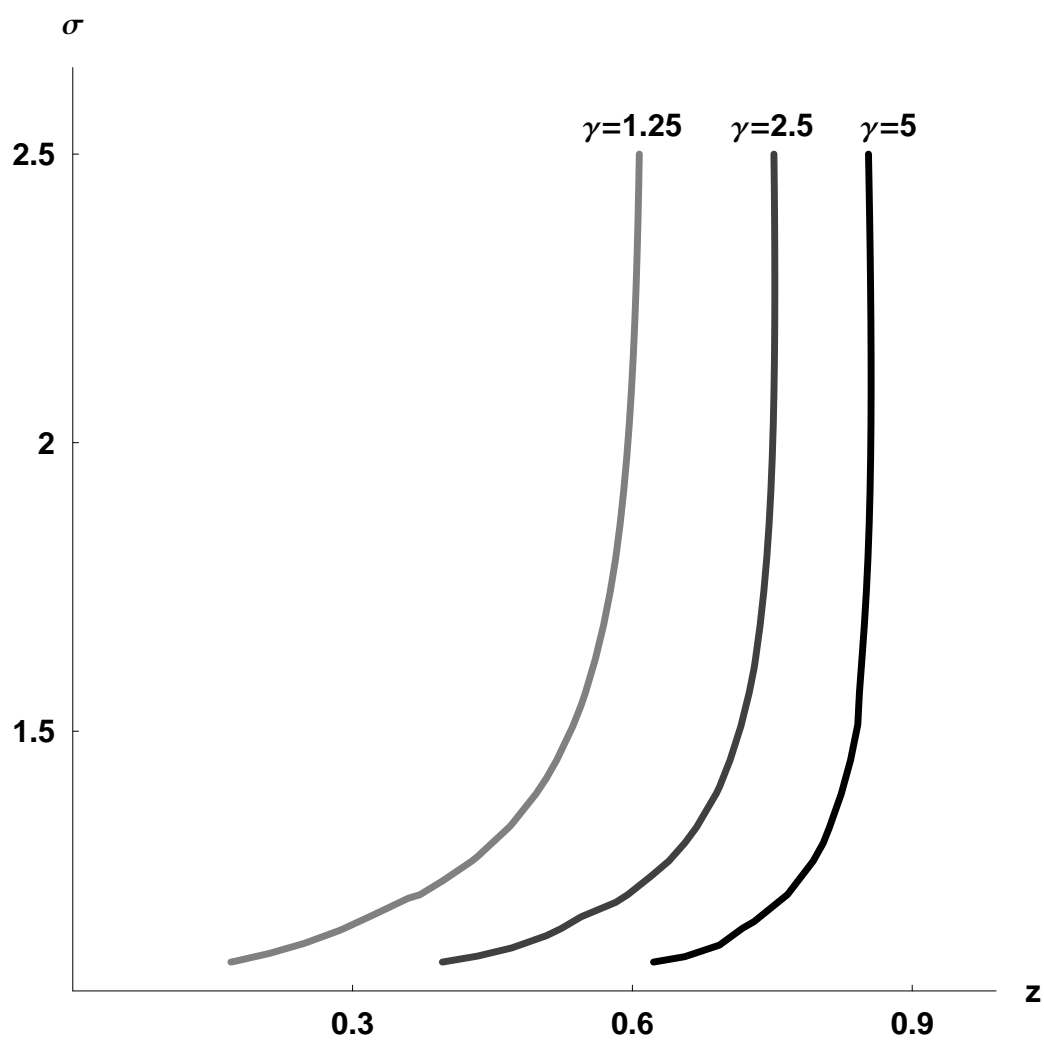

FIGURE 1: LOCI OF INDIFFERENCE BETWEEN A COMMON CURRENCY WITH FIRST-BEST TRANSFERS, $V\left(C_{*}^{c}\right)$, AND A FLEXIBLE EXCHANGE RATE REGIME WITH NO TRANSFERS, E[ $\left.V\left(C^{f}(0)\right)\right]$. THE COMMON CURRENCY DOMINATES FOR LARGER SHOCKS (LOWER $z$ ) AND FOR MORE COMPETITIVE ENVIRONMENTS (HIGHER $\sigma$ ).

such cases the additional risk-sharing benefits that a common currency may directly bring should be taken into account in assessing the choice between fixed versus flexible exchange rate regimes. However we shall adopt the polar assumption that the choice of exchange rate regime does not affect the technology for enforcing risk sharing transfers. We do this not for realism but to show that even in this case there are parameter values such that a common currency area is beneficial. Therefore we can conclude that the affect of a common currency on the enforcement technology is 
not a necessary pre-condition for the optimality of a common currency area when countries share risk.

\subsection{Sustainable Assistance}

As we know that the flexible exchange rate regime dominates if the first-best transfers can be enforced we shall consider situations where first-best transfer cannot be achieved. There may be many reasons for this. We shall consider the case where the first-best transfers cannot be achieved because there is no supra-legal authority to enforce transfer across countries. To allow for the possibility of transfers when commitment is limited we assume that countries interact repeatedly over an infinite horizon. Since transfers cannot be legally enforced, countries can renege on any agreement if they find it in their interest not to make a transfer and hence any assistance programme has to be designed to be self-enforcing. Thomas and Worrall (1988) examine self-enforcing wage contracts between an employer an an employee and a similar approach can be applied here. Thus we presume that countries make a tacit agreement on a programme of mutual assistance and specify a state contingent transfer to be made by the country with the good productivity shock which is received by the country with the bad productivity shock. We shall assume that any breach of this tacit agreement results in a breakdown in which no transfers are made. ${ }^{14,15}$

To consider such self-enforcing transfers between countries $H$ and $F$ let $h_{t}$ denote the history of good and bad outcomes for a particular country. ${ }^{16}$ Let $G^{t}$ denote the good productivity shock outcome at date $t$ and $B^{t}$ denote bad productivity shock outcome at date $t$. Then $h_{t}$ is a list of $G$ 's and $B$ 's where $h_{0}=\emptyset$. An assistance programme in regime $i \in\{c, f\}$ then specifies a transfer $\tau_{B}^{i}\left(h_{t-1}\right)$ to made to the country with the bad productivity shock if the previous history is $h_{t-1}$ and the transfer to be made by the country with the good productivity shock $\tau_{G}^{i}\left(h_{t-1}\right)$. The short-term loss to the country with a good productivity shock of making the required transfer at time $t \geq 1$ relative to making no transfer is $V\left(C_{G}^{i}\left(-\tau_{G}^{i}\left(h_{t-1}\right)\right)\right)-V\left(C_{G}^{i}(0)\right)$.

${ }^{14} \mathrm{~A}$ breakdown in which no transfers are made is the worst possible outcome and is sub-game perfect. It is not however renegotiation-proof. Nevertheless it can be shown that in the current context replacing these punishments with one that are renegotiation-proof will not change the qualitative or quantitative properties of the assistance programme.

15 There are other possible assumptions one could make about behavior in the breakdown. For example a stricter punishment could be imposed whereby there is reversion to trade autarky. Alternatively a weaker punishment would be to assume that following any breakdown in the insurance arrangements there would be a total breakdown of the currency union itself and a return to a flexible exchange rate regime without transfers.

${ }^{16}$ As we have assumed that shocks are perfectly negatively correlated this history has only to be specified for one arbitrary country and is equivalent to specifying a history of states. We are also assuming that all other aspects of the economy are unchanging over time. 
Likewise the short-term gain at date $t \geq 1$ for the country receiving a transfer is $V\left(C_{B}^{i}\left(\tau_{B}^{i}\left(h_{t-1}\right)\right)\right)-V\left(C_{B}^{i}(0)\right)$. To evaluate future gains and losses we shall assume that countries discount the future by a common discount factor $\delta \in(0,1)$. Then the discounted long-term gain from adhering to the agreed transfers from the next period is (discounted back to period $t+1$ )

$\mathrm{E}\left[\sum_{j=0}^{\infty} \delta^{j}\left(\frac{1}{2}\left[V\left(C_{G}^{i}\left(-\tau_{G}^{i}\left(h_{t+j}\right)\right)\right)-V\left(C_{G}^{i}(0)\right)\right]+\frac{1}{2}\left[V\left(C_{B}^{i}\left(\tau_{B}^{i}\left(h_{t+j}\right)\right)\right)-V\left(C_{B}^{i}(0)\right)\right]\right)\right]$

where the expectation $\mathrm{E}$ is taken over all future histories of good and bad productivity shocks from date $t$ onward, $\tau_{G}^{i}\left(h_{t+j}\right)$ is the transfer promised to be made by the country with the good productivity shock at date $t+j+1$ given that the history up to time $t$ was $h_{t}$ and $\tau_{B}^{i}\left(h_{t+j}\right)$ is the transfer to be received by the country with the bad productivity shock at date $t+j+1$ given that the history up to time $t$ was $h_{t}$. Letting $\mathscr{V}_{G}^{i}\left(h_{t}\right)$ denote the net discounted net utility from date $t+1$ for the country with the good productivity shock, i.e. where the history is $h_{t+1}=\left(h_{t}, G^{t+1}\right)$, and $\mathscr{V}_{B}^{i}\left(h_{t}\right)$ be the net utility for a country with a bad productivity shock, i.e. where the history is $h_{t+1}=\left(h_{t}, B^{t+1}\right)$, we have the recursive equations

$$
\begin{aligned}
& \mathscr{V}_{G}^{i}\left(h_{t}\right)=V\left(C_{G}^{i}\left(-\tau_{G}^{i}\left(h_{t-1}\right)\right)\right)-V\left(C_{G}^{i}(0)\right)+\delta\left[\frac{1}{2} \mathscr{V}_{G}^{i}\left(h_{t}, G^{t+1}\right)+\frac{1}{2} \mathscr{V}_{B}^{i}\left(h_{t}, B^{t+1}\right)\right], \\
& \mathscr{V}_{B}^{i}\left(h_{t}\right)=V\left(C_{B}^{i}\left(\tau_{B}^{i}\left(h_{t+j}\right)\right)\right)-V\left(C_{B}^{i}(0)\right)+\delta\left[\frac{1}{2} \mathscr{V}_{G}^{i}\left(h_{t}, G^{t+1}\right)+\frac{1}{2} \mathscr{V}_{B}^{i}\left(h_{t}, B^{t+1}\right)\right] .
\end{aligned}
$$

A country will make a transfer if the expected discounted risk-sharing benefits from future transfers exceed the costs of making the current transfer. Since reneging leads to exclusion, the discounted net utilities must be non-negative at every history

$$
\mathscr{V}_{G}^{i}\left(h_{t}\right) \geq 0 \quad \text { and } \quad \mathscr{V}_{B}^{i}\left(h_{t}\right) \geq 0 \quad \forall h_{t}
$$

We shall say that an assistance programme is sustainable if (12) is satisfied. In addition we shall say that the assistance programme is feasible if $\tau_{G}^{c}\left(h_{t}\right)=\tau_{B}^{c}\left(h_{t}\right)$ for all $h_{t}$ under the common currency regime or $\tau_{G}^{f}\left(h_{t}\right)=z^{\frac{\sigma-1}{\sigma}} \tau_{B}^{f}\left(h_{t}\right)$ under flexible exchange rates.

We next compare the welfare and establish the sustainability conditions for each of the two different exchange rate regimes.

\subsection{Sustainable first best}

In this subsection we consider the discount factors for which the first best-best transfers are sustainable. The first-best transfers are history independent and provide consumption of $C_{*}^{i}$ in both countries. Because the first-best transfers are independent 
of history and because a country will only breach when it has a good productivity shock and is called upon to make a transfer, they are sustainable if and only if

$V\left(C_{*}^{i}\right)-V\left(C_{G}^{i}(0)\right)+\frac{\delta}{(1-\delta)}\left\{\frac{1}{2}\left[V\left(C_{*}^{i}\right)-V\left(C_{G}^{i}(0)\right)\right]+\frac{1}{2}\left[V\left(C_{*}^{i}\right)-V\left(C_{B}^{i}(0)\right)\right]\right\} \geq 0$.

Rewriting this equation shows that these transfers are sustainable for discount factors above a critical level $\bar{\delta}^{i}$ where

$$
\bar{\delta}^{i} \equiv \frac{V\left(C_{G}^{i}(0)\right)-V\left(C_{*}^{i}\right)}{\frac{1}{2}\left[V\left(C_{G}^{i}(0)\right)-V\left(C_{B}^{i}(0)\right)\right]} .
$$

Making use of the constant relative risk aversion specification of preferences given above the critical values of the discount factors above which the first-best transfers are sustainable are independent of $\mu$ and are given by ${ }^{17}$

$$
\bar{\delta}^{f}(z)=\bar{\delta}^{c}\left(z^{\frac{1}{\sigma}}\right)= \begin{cases}2\left(1-\left[\frac{1}{2}\left(1+z^{\frac{\sigma-1}{\sigma}}\right)\right]^{1-\gamma}\right) /\left(1-z^{\frac{\sigma-1}{\sigma}(1-\gamma)}\right) & \text { if } \gamma>1 \\ \left(-\ln (2)+\ln \left(1+z^{\frac{\sigma-1}{\sigma}}\right)\right) / \ln \left(z^{\frac{\sigma-1}{\sigma}}\right) & \text { if } \gamma=1\end{cases}
$$

One can show that for $\gamma \geq 1, \bar{\delta}^{c}(z)$ is a positive and increasing function of $z$ with $\bar{\delta}^{c}(0)=1$ and $\lim _{z \rightarrow 1} \bar{\delta}^{c}(z)=0$. Therefore as $z<z^{1 / \sigma}<1$, we get that $\bar{\delta}^{f}(z)>\bar{\delta}^{c}(z)$ with $\bar{\delta}^{i}(z) \in(0,1)$ for $z \in(0,1)$.

\subsection{Non-sustainability of assistance}

We now consider the case where the two countries $H$ and $F$ cannot sustain any transfers. We first define the ratio of the marginal utility of the country suffering the bad productivity shock to the marginal utility of the country experiencing the good productivity shock when no transfers are made. This is given by

$$
\lambda^{i}(z)=\left.\frac{d V\left(C_{B}^{i}(T)\right) / d T}{d V\left(C_{G}^{i}(T)\right) / d T}\right|_{T=0 .}
$$

With CRRA preferences we have $\lambda^{f}(z)=\lambda^{c}\left(z^{1 / \sigma}\right)=z^{-\gamma(\sigma-1) / \sigma}$ which is again independent of $\mu$. To find circumstances where no transfers are sustainable we need only consider some small and history independent transfers $\tau_{G}^{i}$ and $\tau_{B}^{i}$. As a country will breach when it has a good productivity shock and is called upon to make a

${ }^{17}$ We concentrate now on the case where countries are quite risk averse in that $\gamma \geq 1$. 
transfer, no transfer is sustainable if

$$
\begin{aligned}
& V\left(C_{G}^{i}\left(-\tau_{G}^{i}\right)\right)-V\left(C_{G}^{i}(0)\right) \\
& +\frac{\delta}{(1-\delta)}\left\{\frac{1}{2}\left[V\left(C_{G}^{i}\left(-\tau_{G}^{i}\right)\right)-V\left(C_{G}^{i}(0)\right)\right]+\frac{1}{2}\left[V\left(C_{B}^{i}\left(\tau_{B}^{i}\right)\right)-V\left(C_{B}^{i}(0)\right)\right]\right\}<0 .
\end{aligned}
$$

Approximating the left hand side around no transfers $\left(\tau_{B}^{i}=\tau_{G}^{i}=0\right)$ gives the condition $(1-(\delta / 2))+(\delta / 2) \lambda^{i}(z)<0$. This gives a critical discount factor $\underline{\delta}^{i}$ below which no transfers can be sustained in regime $i \in\{c, f\}$. Using the assumption of constant relative risk aversion preferences gives $\underline{\delta}^{f}=\underline{\delta}^{c}\left(z^{1 / \sigma}\right)=2 /\left(1+z^{-\gamma(\sigma-1) / \sigma}\right)$. One readily can show that $\underline{\delta}^{c}(z)$ is a positive and increasing function of $z$ with $\lim _{z \rightarrow 0} \underline{\delta}^{c}(z)=0$ and $\underline{\delta}^{c}(1)=1$. Therefore $\underline{\delta}^{c}(z)<\underline{\delta}^{f}(z)$. This together with the condition of the previous subsection gives the following result.

PROPOSITION 4: Common currency areas are more likely to sustain an equilibrium with first best transfers and less likely to sustain an equilibrium with zero transfers than flexible exchange rate systems.

Figure 2 depicts the critical discount factors that sustain first best and zero transfers for a set of values of $\sigma, \gamma$ and $\mu$. Below the line $\underline{\delta}^{i}$ no transfers can be sustained in regime $i \in\{c, f\}$. Above the line $\bar{\delta}^{i}$ the first-best transfers can be sustained. For these parameter values of $\sigma$ and $\gamma$ the flexible exchange rate regime can sustain some transfers even for discount factors low enough that the common currency regime cannot sustain the first-best, $\underline{\delta}^{f}<\bar{\delta}^{c}$. However, for different values of $\sigma$ or $\gamma$ it is easy to show that $\underline{\delta}^{f}>\bar{\delta}^{c}$ is possible.

\subsection{Self-enforcing transfers}

Self-enforcing transfers will in general be history dependent. However, the results of Thomas and Worrall (1988) show that the long-run distribution is ergodic. In the case with just two states we have here transfers will be history independent as soon as both states have occurred. It easy to find the transfers after both states have been visited. Either the first-best transfer is sustainable or no transfer is sustainable or the transfer will be set so that (13) is binding. This is easy to see as if equation (13) weren't binding the transfer could be increased slightly and welfare could be improved.

Suppose that the parameters are such that the first-best transfer is not sustainable but that some self-enforcing transfers are sustainable. To determine the self-enforcing 


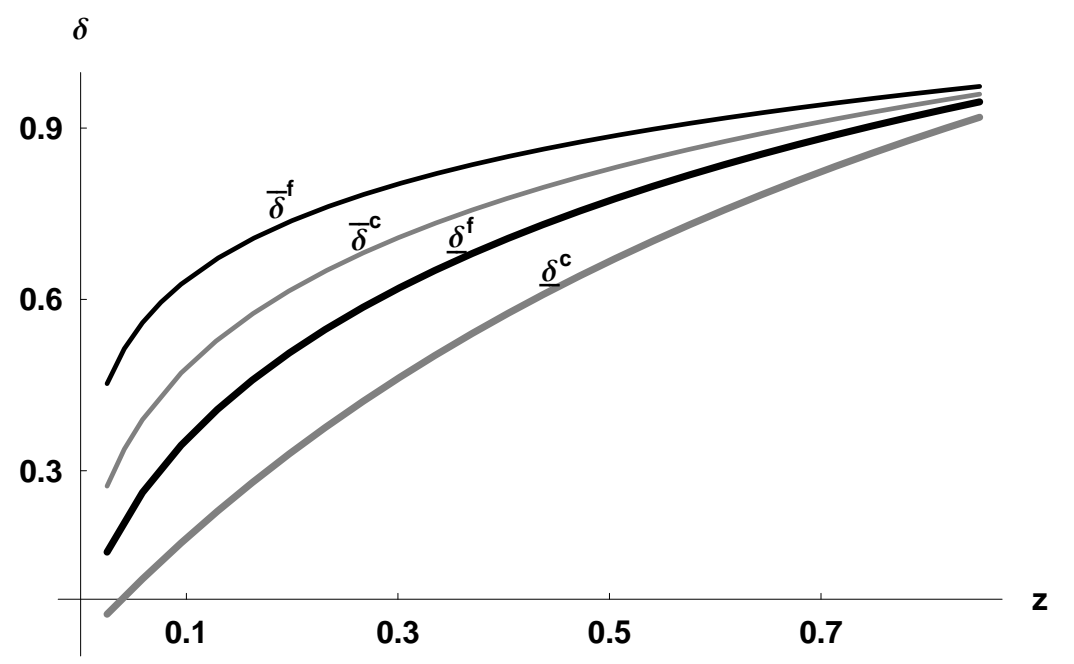

FIGURE 2: MAXIMUM AND MINIMUM DISCOUNT FACTORS WHICH SUSTAIN NO TRANSFERS OR FIRST-BEST TRANSFERS: $\gamma=2, \mu=0.05$ AND $\sigma=1.5$.

transfer the simply involves solving the equation

$$
\phi^{i}\left(z, \tau^{i}\right) \equiv \frac{V\left(C_{B}^{i}\left(\tau_{B}^{i}\right)\right)-V\left(C_{B}^{i}(0)\right)}{V\left(C_{G}^{i}(0)\right)-V\left(C_{G}^{i}\left(-\tau_{G}^{i}\right)\right)}=\frac{2-\delta}{\delta}
$$

where $\tau^{i}=\tau_{G}^{i}$ is the transfer made by the country with the good productivity shock and where $\tau_{B}^{c}=\tau_{G}^{c}$ and $\tau_{B}^{f}=z^{\frac{\sigma-1}{\sigma}} \tau_{G}^{f}$.

PROPOSITION 5: There is a unique value of $\tau^{i}$ satisfying equation (14) and this value is strictly increasing in $\delta$.

With CRRA preferences the function $\phi^{i}\left(z, \tau^{i}\right)$ simplifies considerably so that the transfer $\tau^{i}$ can be found by solving the involves solving the equations

$$
\phi^{c}\left(z, \tau^{c}\right)=\phi^{c}\left(z^{\frac{1}{\sigma}}, \tau^{f}\right)=\frac{(2-\delta)}{\delta}
$$

where

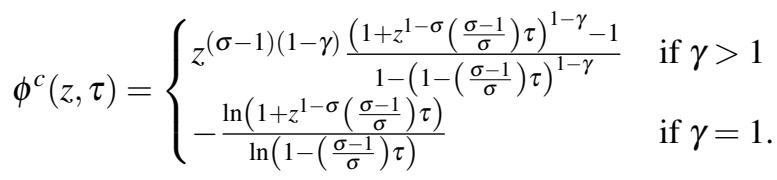


With this specification it is clear that since $z^{1 / \sigma}<z$ we have that $\tau^{f}<\tau^{c}$ so that a greater transfer can be sustained under a currency union that under a flexible exchange rate. In addition it is possible to show that $\phi^{i}\left(z, \tau^{i}\right)$ is strictly decreasing in $z$. Thus a larger shock (smaller value of $z$ ) will mean that a larger transfer $\tau^{i}$ can be sustained.

PROPOSITION 6: The larger the productivity shock the greater will be the transfer that is sustained in either regime. The common currency union will sustain a greater transfer than the flexible exchange rate regime.

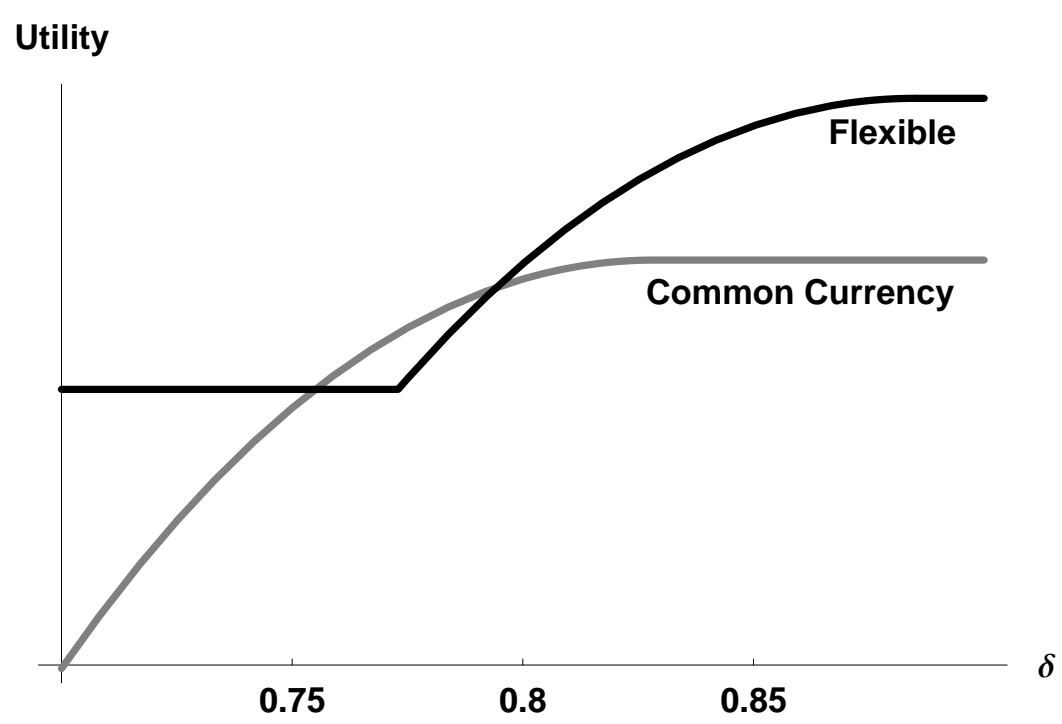

FIGURE 3: WELFARE COMPARISONS FOR THE COMMON CURRENCY AND FLEXIBLE EXCHANGE RATE REGIMES WITH OPTIMAL SUSTAINABLE TRANSFERS: $\gamma=2, \mu=0.05, \sigma=1.5$. AND $z=0.5$.

As it is not possible to obtain an explicit solution for $\tau^{i}$ in equation (15) it is difficult to give analytical results of the effect of the different regimes on welfare. We know from Propositions 4 and 6 that the common currency regime sustains greater transfers. However, we also know from Propositions 1 and 2 that the flexible exchange rate system will generate greater welfare if either no transfers or the first-best transfers can be sustained. Thus in comparing welfare there are two opposing effects. The common currency area allows for greater transfers and thus greater sharing of risk and greater welfare. However it does not allow the inefficiencies in the labor market 
to be offset by adjustments in the exchange rate and this tends to lower welfare. Using equation (15) however, it is possible to compute the maximum sustainable transfers for any discount factor and hence compute the expected welfare of each country under flexible exchange rates or a common currency.

Computations show that either effect can dominate. Thus for some parameter values a flexible exchange rate regime generates greater welfare and for other parameter values a common currency does. As the first-best transfers can be sustained under common currency when less or no transfers can be sustained with flexible exchange rates, there are many parameter values for which higher welfare can be achieved with a common currency than with flexible exchange rates. More interesting perhaps are cases where the common currency cannot sustain first-best transfer, the flexible exchange rate regime can support some transfers but where the common currency yields higher welfare for some parameter values. Such an example is illustrated in Figure 3. The darker line plots the welfare under flexible exchange rates against the discount factor. It is initially horizontal and here no transfers can be sustained but then it rises as some transfers can be sustained and it is again horizontal for higher discount factors when the first-best transfers can be sustained. The lighter line represents expected utility under common currency and it has a similar shape (the lower part where no transfers can be sustained is not illustrated). Following on from Propositions 1 and 2 it is clear that flexible exchange rates dominate for low discount factors where no transfers can be sustained in either regime of for high discount factors where first-best transfers can be sustained in either regime. However, as can be seen the common currency regime does produce higher welfare in an intermediate range of discount factors where neither regime can sustain the first-best transfers.

In our opinion, this result is important and novel as it sheds light on a force that has not been carefully analyzed in the previous literature. That is, transfers that share risk between countries can be larger and easier to implement in a common currency area than in a flexible exchange rate regime. The force behind the need of countries to share risk can outweigh the short term opportunistic gain of countries from not making a transfer when called upon to do so. As explained in the introduction we have abstracted from other forces that may favor a common currency such as the removal of exchange rate transaction costs, the elimination of competitive inflation and the increased stability of financial markets. Our view is that the results of this paper show that the issue of currency integration cannot be divorced from the issue of fiscal integration through risk sharing. The next section will attempt to reinforce this conclusion by examining the robustness of the result to a number of possible alternative specifications of the model. 


\section{EXtensions}

The model can be extended in a number of directions without changing the substantive result that considerations of sustainable assistance are important in determining the relative efficiency of common currency and flexible exchange rate systems. This section outlines some possible extensions.

\subsection{Additional tradable sectors}

In the model outlined both the Home and Foreign countries compete in all goods produced. Suppose there are specialized but tradable commodity sectors in each country. Let $Z_{r}$ be the output of specialized locally produced goods in country $r$. For simplicity consider only trade between $H$ and $F$ (set $\mu=1$ ) and suppose that the constant elasticity of substitution preferences utility becomes

$$
V\left(C_{r}\right)=V\left(\left(\int_{0}^{1} d_{r r}(\varsigma)^{\frac{\sigma-1}{\sigma}} d \varsigma+\int_{0}^{1} m_{s r}(\xi)^{\frac{\sigma-1}{\sigma}} d \xi\right)^{\frac{\sigma \chi}{\sigma-1}} Z_{r}^{\frac{1-\chi}{2}} Z_{s}^{\frac{1-\chi}{2}}\right)
$$

where $(1-\chi)$ is the share of the specialized sectors (which for simplicity we've assumed is evenly distributed between the two countries). Assuming that the two tradable sectors have constant returns to scale and hire workers who produce at unit productivity, labor demand is $\ell_{r}=a_{r} d_{r}+Z_{r}$ and gross domestic product $Y_{r}=p_{r} d_{r}+Z_{r}$. Prices of the competitively produced manufacturing goods is the same as before $p_{r}=a_{r} \sigma /(\sigma-1)$ and the size of the specialized sectors is $Z_{H}=(1-\chi)\left(Y_{H}+\varepsilon Y_{F}\right) / 2=\varepsilon Z_{F}$. Then one can show that

$$
Y_{H}=\frac{\sigma}{\sigma-1} \ell_{H}\left[1-\frac{(1-\chi)}{2} \frac{1}{\sigma-\chi}\left(1+\varepsilon \frac{\ell_{F}}{\ell_{H}}\right)\right]
$$

with a similar expression for $Y_{F}$. Equating demand and supply then gives the following implicit condition for the exchange rate.

$$
\left(\frac{a_{H}}{a_{F}}\right)^{1-\sigma}=\varepsilon^{1-\sigma}\left[\frac{(\sigma-\chi) \ell_{H}-\frac{1}{2}(1-\chi) \sigma\left(\ell_{H}+\varepsilon \ell_{F}\right)}{(\sigma-\chi) \varepsilon \ell_{F}-\frac{1}{2}(1-\chi) \sigma\left(\ell_{H}+\varepsilon \ell_{F}\right)}\right] .
$$

One can see that for $\chi=1$, equations $\left(7^{\prime}\right)$ and $\left(9^{\prime}\right)$ reduce to equations (7) and (9) respectively. In the common currency case $\varepsilon=1$ and either $\ell_{H}$ or $\ell_{F}$ is less than one depending on the technology parameters $a_{H}$ and $a_{F}$. In the flexible exchange rate case there is full employment with $\ell_{H}=\ell_{F}=1$. As expected experimentation shows that common currency areas is more likely to dominate for a large tradable sector $\chi$. Yet the effect of $\chi$ in the examples we computed is not very significant. 


\subsection{Transactions costs}

It is possible to introduce transactions costs into the analysis of the flexible exchange rate regime by allowing for a bid-ask spread. The bid-ask spread can be taken fixed percentage $\theta$ where $\varepsilon^{\text {bid }} / \varepsilon^{a s k}=1-\theta$. The introduction of a bid-ask spread has two effects that reduce the attractiveness of the flexible exchange rate regime. First foreign goods become relative more expensive reducing the efficiency gains from trade. Secondly, some of the transfer is lost in transaction and so insurance is also less effective in the flexible exchange rate regime.

\subsection{Alternative threats}

We have made two particular assumptions about the threat or punishment to be imposed after a country has defected from the tacit agreement on transfers. First, it has been assumed that countries are threatened with complete exclusion if they defect. Secondly, it has been assumed that countries maintain their participation in the currency area after their defection so that they suffer more from larger real income shocks. The first assumption is not that critical. A threat of partial or temporary exclusion will lead to similar results although reduce risk-sharing and hence the attractiveness of the common currency regime relative to the flexible exchange rate regime.

The second assumption is plausible in many existing currency areas where nations or jurisdictions have no effective central banks and where the political and credibility cost of issuing a new currency is large. In practice much risk-sharing takes place at the regional or sub-national level. For example, discussions about risk sharing and redistribution take place between autonomous communities in Spain, between provinces in Canada and, between regions in Belgium and Italy. The costs of issuing a new currency is undoubtedly very high at this jurisdictional level and the assumption that the default maintains the common currency is probably justified.

Nevertheless, it is worth considering an alternative assumption for the sake of our discussion. Suppose then that a defecting country quits the common currency area, creates its own currency at no cost and implements an exchange rate policy that cushions its income fluctuations. In this case the threat of punishment after defection is diminished and the incentives to adopt common currency are smaller. However, in this case one should also consider other costs associated with defection. Currency areas are usually associated with trade advantages (e.g. zero tariffs, non discrimination clauses, common legislation, etc.) and other benefits from common policies and public goods offered within the area (e.g. common defense policy, freedom of capital and labor movements). A country reneging in these circumstances is likely to lose these benefits and may suffer additional trade and other political 
sanctions. In this paper we have deliberately abstracted from these considerations to concentrate on pure risk sharing considerations.

\subsection{Alternative stochastic processes}

We have assumed that shocks in the two countries $H$ and $F$ are perfectly negatively correlated. This is mainly for convenience and because it is known that under standard assumptions without insurance this is the case in which a flexible exchange rate regime is most dominant. The assumption of perfect negative correlation and symmetry (together with the assumption of constant relative risk aversion) also allowed us to derive some simple analytic formulae for critical discount factors.

It is possible to generalize the stochastic process and allow for any degree of correlation between shocks and also allow for persistence of shocks within countries. With a small number of states it is still possible to obtain analytical solutions. With a larger number of states it is necessary to compute solutions by numerically by interpolating the appropriate value function. This is not too computationally expensive if the number of states is not too large. There is however the further difficulty that with increases in the number of states the time taken to the steady-state becomes longer, so that an appropriate comparison is not with the steady-state but with the long-run expected discounted utility including the transition to the steady-state.

\subsection{Labor market imperfections}

A restrictive assumption of the analysis is that nominal wages are completely inflexible and this stands in contrast to our assumption that the product market is monopolistically competitive. It would be possible to introduce some wagesetting behavior to the model (see for example Danthine and Hunt 1994) to relax this assumption. Introducing wage setting would have two opposing effects. First introducing some flexibility into the labor market would make the currency union more attractive as the inefficiency in the labor market is reduced. Secondly it would make the punishment of returning to zero transfers less severe and hence reduce the amount of insurance that could be sustained. The net effect of reducing the labor market imperfections in the model is therefore ambiguous and something for further analysis.

\subsection{Access to capital market}

Our model aims to explain the emergence of voluntary transfers and the benefit of more sustainable risk sharing mechanisms in a currency area. The risk sharing need arises because countries and workers are unable to fully insure their idiosyncratic risks in a capital market. Yet the capital market can be a means to diversify risk. There is an incentive to write formal contracts to hedge a share of the income risk 
against that of the other country. Such hedging contracts are however, rare in practice (French and Poterba 1991). This may because of moral hazard or precisely because of the transnational enforcement difficulties that are the focus of this paper. The difficultly to enforce such hedging contracts at a international level is also discussed in Drèze (2000).

Nevertheless, it is possible to consider a simple version of an international capital market where domestic workers take a full shareholder participation in foreign firms. In this case domestic national income includes the domestic wage bill and the share of foreign profit so that $Y_{H}=\ell_{H}+\varepsilon \ell_{F} /(\sigma-1)$. World income $Y$ and the nominal prices remain unaffected. As a result, the exchange rates $(\varepsilon, \eta)$ and employment levels $\left(\ell_{H}, \ell_{F}\right)$ are given by the same formulae as above. The important point to note here is that the share of participation in foreign profits on the workers' wage, $\varepsilon\left(\ell_{F} / \ell_{H}\right) /(\sigma-1)$, decreases with product substitution (larger $\left.\sigma\right)$ and thus with the firms' competitive environment. As a result, more competitive environments make full participation in foreign profits a less effective risk sharing instrument, although they make risk sharing even more valuable for countries and workers. Finally, observing that common currency areas are more likely to be sustainable in more competitive environments (larger $\sigma$ ), we can readily infer that our result about the optimality of common currency area still applies for very competitive environments. So, the impact of workers' participation in the stock market on the optimality of the common currency area crucially depends on the degree of competitiveness.

\section{CONCLUSIONS}

This paper has examined the importance of inter-country mutual insurance on the decision to adopt either a common currency or a flexible exchange rate system. Standard analysis suggests that absent any transactions costs the flexible exchange rate system will dominate if either there is no insurance or alternatively if there is full insurance. However, we have shown that if there are restrictions caused by commitment constraints so that only partial insurance is achievable then this result can be reversed and a common currency can generate higher welfare. The impediment to full insurance we have assumed is that there is no supra-national authority to enforce insurance payments across countries and therefore such insurance must be self-enforcing. The imposition of the constraints of self-enforcement mean that sometimes more insurance can be enforced under a common currency system than a flexible exchange rate system because the threat of no future insurance if there is a breakdown in transfers is more severe in the common currency case.

The paper has presented a simple model to illustrate this possibility. There has been no attempt to calibrate the model as realistic calibration would require a much more 
sophisticated model of both production and labor market imperfections and a more detailed specification of the stochastic structure of shocks. Rather we illustrate the importance of insurance on the currency union in a model designed to make currency union a priori less desirable. Thus we assumed that there were no transactions costs in the flexible exchange rate system, there was perfect inflexibility in the labor market and shocks were perfectly negatively correlated. Despite these assumptions it has been shown that there are parameter values where a common currency can generate greater welfare. The result should be of interest to policy makers as it shows that any agreement on a system of insurance or fiscal transfers between countries can have an important impact on the monetary decision to adopt a common currency.

\section{APPENDIX}

Proof of Proposition 1: Take the case $a_{H}<a_{F}$. We have

$$
\begin{aligned}
& C_{H}^{f}(0)=\mu\left(a_{H}^{1-\sigma}+\varepsilon^{1-\sigma} a_{F}^{1-\sigma}\right)^{\frac{\mu}{\sigma-1}}(1+\varepsilon)^{\mu-1} \\
& C_{H}^{c}(0)=\mu\left(a_{H}^{1-\sigma}+a_{F}^{1-\sigma}\right)^{\frac{\mu}{\sigma-1}}\left(1+\left(\frac{a_{H}}{a_{F}}\right)^{\sigma-1}\right)^{\mu-1} .
\end{aligned}
$$

Since $a_{H}<a_{F}, \varepsilon^{1-\sigma}>1$ and $\varepsilon>\left(a_{H} / a_{F}\right)^{\sigma-1}$. Hence $C_{H}^{f}(0)>C_{H}^{c}(0)$. Also

$$
C_{H}^{f}(0)=\varepsilon C_{H}^{f}(0) \quad \text { and } \quad C_{H}^{c}(0)=\left(\frac{a_{H}}{a_{F}}\right)^{\sigma-1} C_{H}^{c}(0) .
$$

Since $\varepsilon>\left(a_{H} / a_{F}\right)^{\sigma-1}$ this shows that $C_{F}^{f}(0)>C_{F}^{c}(0)$. A similar argument applies in the case where $a_{H}>a_{F}$.

Proof of Proposition 2: Rewriting the formulas above for the composite consumptions so that they can be compared gives

$$
C_{*}^{c}=\frac{1}{2} \mu z^{-\mu}\left(1+z^{\sigma-1}\right)^{\frac{\mu \sigma}{\sigma-1}} \quad \text { and } \quad C_{*}^{f}=\frac{1}{2} \mu z^{-\mu}\left(1+z^{\frac{\sigma-1}{\sigma}}\right)^{\frac{\mu \sigma}{\sigma-1}} .
$$

Since $z^{\frac{\sigma-1}{\sigma}}>z^{\sigma-1}$ for $z<1$ and $\sigma>1$ it follows that $C_{*}^{f} \geq C_{*}^{c}$.

ProOf OF Proposition 3: To compare the two alternatives define the relative risk premium $\rho(z)$ by

$$
V\left(C_{*}^{f}(1-\rho(z))=\mathrm{E}\left[V\left(C^{f}(0)\right)\right]=\frac{1}{2} V\left(C_{B}^{f}(0)\right)+\frac{1}{2} V\left(C_{G}^{f}(0)\right) .\right.
$$


A country will prefer a currency area with full transfers over a flexible exchange rate with no transfers if $V\left(C_{*}^{c}\right)>V\left(C_{*}^{f}(1-\rho(z))\right.$ or $\rho(z)>1-\left(C_{*}^{c} / C_{*}^{f}\right)$. Let $\rho_{\gamma}(z)$ denote the relative risk premium associated with a constant relative risk aversion utility function with coefficient $\gamma>0$. Now consider whether there are always shocks large enough such that $\rho_{\gamma}(z)>1-\left(C_{*}^{c} / C_{*}^{f}\right)$ even for very low degrees of risk aversion. Let $h(z)=1-\left(C_{*}^{c} / C_{*}^{f}\right)$. Both $h(z)$ and $\rho_{\gamma}(z)$ are positive and continuous and continuously differentiable functions. We shall substitute using the monotonic transformation $q=z^{(\sigma-1) / \sigma}$ where $q \in[0,1]$ as $z \in[0,1]$. Then writing $\rho_{\gamma}$ and $h$ as functions of $q$ it follows that $\rho_{\gamma}(q)=1-2^{\gamma /(\gamma-1)}\left(1+q^{1-\gamma}\right)^{1 /(1-\gamma)}(1+q)^{-1}$ and $h(q)=1-\left(\left(1+q^{\sigma}\right)(1+q)^{-1}\right)^{\mu \sigma /(\sigma-1)}$. It can be shown that $h(q)$ is concave and $\rho_{\gamma}(q)$ is decreasing and convex. Moreover, $\rho_{\gamma}(q)$ and $h(q)$ are contained in the range $[0,1]$. The function $\rho_{\gamma}(q)$ has limit properties $\lim _{q \rightarrow 1} \rho_{\gamma}(q)=0$, $\lim _{q \rightarrow 1} \rho_{\gamma}^{\prime}(q)=0, \lim _{q \rightarrow 0} \rho_{\gamma}(q)=1-2^{\gamma /(\gamma-1)}$ if $1>\gamma>0, \lim _{q \rightarrow 0} \rho_{\gamma}(q)=1$ when $\gamma \geq 1, \lim _{q \rightarrow 0} \rho_{\gamma}^{\prime}(q)=-\infty$ if $1 \geq \gamma>0$ and $\lim _{q \rightarrow 0} \rho_{\gamma}^{\prime}(q)=-2^{\gamma /(\gamma-1)}$ if $\gamma>1 . h(q)$ is not monotone with a maximum when $\left(1+q^{\sigma}\right)=\sigma q^{\sigma-1}(1+q)$. The limit properties of $h(q)$ are $\lim _{q \rightarrow 0} h(q)=0, \lim _{q \rightarrow 0} h^{\prime}(y)=\mu \sigma /(\sigma-1), \lim _{q \rightarrow 1} h(q)=0$ and $\lim _{q \rightarrow 1} h^{\prime}(q)=-\mu \sigma / 2$. From these properties it is easy to see that $\rho_{\gamma}(q)$ and $h(q)$ intersect once for some $\hat{q} \in[0,1]$. Thus for $z<\hat{z}=q^{\sigma /(\sigma-1)}$ we have $\rho_{\gamma}(z)>h(z)$ and the common currency area with full risk-sharing dominates the flexible regime with no transfers with the reverse true for $z>\hat{z}$.

Proof of Proposition 5: Consider the case of the currency union. Differentiating $\phi^{c}\left(z, \tau^{c}\right)$ with respect to $\tau^{c}$ shows that

$$
\operatorname{sign} \frac{\partial \phi^{c}\left(z, \tau^{c}\right)}{\partial \tau^{c}}=\operatorname{sign} \frac{V^{\prime}\left(C_{B}^{c}\left(\tau^{c}\right)\right)}{V^{\prime}\left(C_{G}^{c}\left(-\tau^{c}\right)\right)}-\phi^{c}\left(z, \tau^{c}\right) .
$$

By the concavity of $V$ we have for any $\tau^{c} \in\left(0, \tau_{*}^{c}\right)$,

$$
\frac{V\left(C_{B}^{i}\left(\tau_{B}^{i}\right)\right)-V\left(C_{B}^{i}(0)\right)}{C_{B}^{c}\left(\tau^{c}\right)-C_{B}^{c}(0)}>V^{\prime}\left(C_{B}^{c}\left(\tau^{c}\right)\right)>V^{\prime}\left(C_{G}^{c}\left(-\tau^{c}\right)\right)>\frac{V\left(C_{G}^{i}(0)\right)-V\left(C_{G}^{i}\left(-\tau_{G}^{i}\right)\right)}{C_{G}^{c}(0)-C_{G}^{c}\left(-\tau^{c}\right)} .
$$

In varying $\tau^{c}, C_{G}^{c}(0)-C_{G}^{c}\left(-\tau^{c}\right)=C_{B}^{c}\left(\tau^{c}\right)-C_{B}^{c}(0)$ and hence

$$
\frac{V^{\prime}\left(C_{B}^{c}\left(\tau^{c}\right)\right)}{V^{\prime}\left(C_{G}^{c}\left(-\tau^{c}\right)\right)}-\phi^{c}\left(z, \tau^{c}\right)<0
$$

Thus $\phi^{c}\left(z, \tau^{c}\right)$ is monotonically decreasing in $\tau^{c}$ and hence there is a unique value of $\tau^{c}$ satisfying equation (14). As the right hand side of equation (14) is strictly 
decreasing in $\delta \in(0,1)$ the transfer that can be sustained is strictly increasing in $\delta$. The proof for the flexible exchange rate case is similar.

ACKnowledgements: We thank Michael Artis, Jacques Drèze, Paul De Grauwe and Jacques Melitz for fruitful discussions. The second author gratefully acknowledges the support of the Hallsworth Research Fellowship Fund at the University of Manchester. 


\section{REFERENCES}

Alesina, A., Perotti, R. and Spolaore, E. (1995). Together or separately? Issues on the costs and benefits of political and fiscal unions. European Economic Review, 39 (3), 751-758.

BAXTER, M. and JERMAnN, U. J. (1997). The international diversification puzzle is worse than you think. American Economic Review, 87 (1), 170-180.

BAyOumi, T. A. (1994). A formal theory of optimum currency areas. IMF Staff Papers, 42 (4), 537-554.

DAnTHINE, J.-P. and HunT, J. (1994). Wage bargaining structure, employment and economic integration. The Economic Journal, 104 (424), 528-541.

Dixit, A. K. and Stiglitz, J. E. (1977). Monopolistic competition and optimum product diversity. American Economic Review, 67 (3), 297-308.

DrÈzE, J. H. (2000). Economic and social securtiy in the twenty-first century, with attention to Europe. Scandinavian Journal of Economics, 102 (3), 327-348.

ForNi, M. and REICHLIN, L. (1999). Risk and potential insurance in Europe. European Economic Review, 43 (7), 1237-1256.

FRENCH, K. R. and PoterbA, J. M. (1991). Investor diversification and international equity markets. American Economic Review, 81 (2, Papers and Proceedings), 170-180.

Mundell, R. A. (1961). A theory of optimum currency areas. American Economic Review, 51 (4), 657-665.

Persson, T. and Tabellini, G. (1996). Federal fiscal constitutions: Risk sharing and moral hazard. Econometrica, 64 (3), 623-646.

Thomas, J. P. and WorRALL, T. (1988). Self-enforcing wage contracts. Review of Economic Studies, 55 (4), 541-554. 